\title{
SABERES E VIVÊNCIAS NA FORMAÇÃO DE EDUCADORES AMBIENTAIS AMAZÔNICOS
}

\author{
Raimunda kelly Silva Gomes ${ }^{1}$, Vitor Sousa Cunha Nery ${ }^{2}$, Angela do Céu Ubaiara Brito ${ }^{3}$
}

\begin{abstract}
RESUMO
Este artigo teve como objetivo compreender os saberes docente como pilar para a formação de educadores amazônicos, apontando proposta para a inserção da educação ambiental em suas práxis educativas, a partir de uma vertente holística e/ou socioambiental. Os resultados mostram que que a implementação de uma estratégia pedagógica que possibilite a aproximação entre os educadores no ambiente escolar, talvez seja uma alternativa de integração das atividades curriculares com os saberes e vivências dos educandos, tendo o grupo focal como estratégia metodológica de aproximação e dialogo no ambiente escolar. Portanto, a EA no contexto escolar deve levar em conta a dinâmica de seus contextos socioambientais e culturais, entendendo os professores como profissionais que têm saberes e concepções construídas na práxis.
\end{abstract}

Palavras-chave: saberes, educação ambiental, práxis educativa, Amazônia.

\begin{abstract}
This article aimed to understand teacher knowledge as a pillar for the training of Amazonian educators, pointing out a proposal for the insertion of environmental education in their educational practices, from a holistic and / or socioenvironmental perspective. The results show that the implementation of a pedagogical strategy that makes it possible to approach educators in the school environment is perhaps an alternative of integrating curricular activities with the learners' knowledge and experiences, with the focus group as a methodological strategy for approach and dialogue in the school environment. Therefore, EE in the school context must take into account the dynamics of its socio-environmental and cultural contexts, understanding teachers as professionals who have knowledge and conceptions built in praxis.
\end{abstract}

Keywords: knowledge, environmental education, educational praxis, Amazon

\footnotetext{
${ }^{1}$ Graduação em Pedagogia pela Universidade Federal do Pará (2006). Mestre em Biologia Ambiental, pela UFPA (2008). Atualmente é docente da Universidade do Estado do Amapá, curso de licenciatura em Pedagogia, e líder do grupo de pesquisa de integração socioambiental e educacional na Amazônia amapaense.

${ }^{2}$ Doutorando em Educação (UFPA, 2016), Mestre em Educação na modalidade sanduíche (UEPA/PUCRio, 2013 e Graduado em Licenciatura Plena em Pedagogia (UEPA, 2010) e Tecnologia em Gestão Pública (UNAMA, 2009). Atualmente atua como Professor efetivo da Universidade do Estado do Amapá (UEAP). Líder do Grupo de Estudos e Pesquisas em Educação na Amazônia Amapaense (GEPEAUEAP).

${ }^{3}$ Doutora em Educação pela Universidade de São Paulo- USP (2013), Mestre em Direito Ambiental e Políticas Públicas pela Universidade Federal do Amapá- UNIFAP (2008) e graduada em Licenciatura Plena em Pedagogia pela Universidade Federal do Amapá- UNIFAP (1999). Atualmente é professora da Universidade do Estado do Amapá, atua no Colegiado de Pedagogia (UEAP).
} 


\section{INTRODUÇÃO}

Os espaços de reflexões e atuação da Educação Ambiental (EA) na educação formal foram pensados para atender às necessidades básicas do sistema educacional, o que contribuiu para a sua marginalização, tanto nas práticas educativas docentes como nos planejamentos curriculares das instituições escolares, uma vez que ela tem sido priorizada numa vertente tradicional de educação, dentro da lógica e da racionalidade estabelecida pelos sistemas de ensino (LEFF, 2010).

Em contraponto, como proposta educativa a educação ambiental surge da consciência das limitações do processo civilizatório moderno, fundamentado em reflexões sobre o modelo de exploração dos recursos naturais e das relações humanas estabelecidas com a natureza, articulando o conhecimento e a transformação social, para garantir o equilíbrio na formação cidadã, atribuindo à escola a responsabilidade de integração dos conteúdos curriculares aos problemas socioambientais existentes. Portanto, as contribuições das teorias críticas à EA, em relação à teoria educacional, podem ser considerada uma crítica a todas as pedagogias divergentes da prática educativa tradicional marcada por:

\footnotetext{
Uma organização curricular fragmentada e hierarquizada, neutralidade do conhecimento transmitido e produzido; e organização escolar e planejamento do processo de ensino e aprendizagem concebidos como pura racionalidade, pautados em finalidades pedagógicas desinteressadas quanto às implicações sociais de suas práticas. (LOUREIRO, 2006, p. 52)
}

Neste sentido, Carvalho (2012) ressalta que a EA possibilita alternativas renovadoras no sistema de ensino, de organização e dos conteúdos escolares, pautandose numa revisão da instituição e do cotidiano escolar, mediante os atributos da transversalidade e da interdisciplinaridade, articulando os processos pedagógicos com os conhecimentos ambientais, através da interdisciplinaridade dos sujeitos e de sua relação com a natureza.

Para Tozonni-Reis (2008), a educação e particularmente a escola, em todos os níveis tem por função preparar os indivíduos para atuarem na sociedade, respeitando suas características de desenvolvimento. As atitudes e valores apontados como importantes conteúdos educativos, especialmente na EA, são tidos como universais, onde a readequação dos espaços escolares, deve possibilitar a flexibilização do currículo, através de processos participativos (TORALES, 2013). 
Entretanto, Gazzinelli (2002) ressalta que a formulação da EA formal ocorreu de forma isolada, não considerando as projeções da temática na formação do cidadão no espaço formal, e as possibilidades dadas aos professores e ao aluno, para a construção de representações mais apropriadas a um novo significado é um papel a ser desempenhado por eles no domínio ambiental, uma vez que os conteúdos da EA se integrariam ao currículo escolar, a partir de uma relação de transversalidade, de modo a impregnar a prática educativa, exigindo dos professores uma readaptação dos conteúdos abordados na sua disciplina, inter-relacionando com as questões socioambientais locais, pois a temática ambiental, poderia ser objeto de estudo de todos os componentes curriculares.

Diante disso, consideramos que somente através de um processo educativo é possível alcançar a sustentabilidade, entretanto, questionamos: A quem atribuiríamos a responsabilidade da EA no currículo escolar? Pode ser concebida uma educação que transcenda os muros da escola? Há a possibilidade de pensar/propor uma educação transversal no cotidiano educativo?

\section{A FORMAÇÃO DE EDUCADORES AMBIENTAIS PARA EFETIVAÇÃO DA EA NA PRÁXIS EDUCATIVA}

Atualmente, é necessário novas visões de mundo, através de uma educação com abordagens didático-pedagógicas diferenciadas, voltada para a construção de uma cidadania planetária, pois educar ambientalmente, hoje vai além de sensibilizar a população para os problemas existentes, é preciso o exercício pleno da cidadania em um processo de conscientização (consciência + ação), para exteriorizar em ações, aquilo que interiorizamos (razão e emoção) para uma reflexão crítica (TOZONNI-REIS, 2008; GUIMARÃES, 2011; TEIXEIRA e TORALES, 2014).

Assim, a EA na formação de educadores assume o desafio de provocar mudanças na vida cotidiana dos indivíduos, dando ressignificação a relação do homem com a natureza e ao seu modo de vida (LEFF, 2010), compreendendo a importância da educação para a cidadania planetária e, consequentemente, para um futuro sustentável.

Sabe-se que a compreensão da EA, pelas vivências dos educadores ambientais, possibilita a constituição da identidade socioambiental e política que consolidam as 
ISSN- 1413-8638

E-ISSN - 2238-5533

v. 22 , n. 2, p. 173-190, 2017

reflexões cotidianas, para tanto é necessário que o educador compreenda a EA em sua complexidade, para a transformação das relações entre sociedade e ambiente.

Para Carvalho (2012) a existência de um sujeito ecológico passa a credibilidade de que é possível um mundo transformado, em que a constituição de uma atitude ecológica concreta, possa servir de incentivo para a formação de educadores ambientais. No entanto, Tozonni-Reis (2008) alerta que essa formação é um processo de transmissão de valores e atitudes, no qual a preocupação com a formação cultural, são os principais indicadores da representação da educação, através da subjetividade humana.

Nesta perspectiva, a atitude ecológica e cidadã implicam em um processo de reflexão-ação, pois o que fazer e como fazer, nem sempre garantem a formação de uma atitude ecológica, isto é, de sistemas de valores sobre como se relacionar com o ambiente, os quais serão concretizados de acordo com o posicionamento do sujeito na escola e em outros espaços e circunstâncias de sua vida (AB' SABER, 1994).

A EA, enquanto tendência educacional, vislumbra inter-relacionar os aspectos ambientais aos educativos, possibilitando a formação de educadores ambientais, que valoriza a diversidade cultural, evidenciada no PRONEA, ao considerar a temática meio ambiente fundamental no fazer educativo docente; pois, devem assumir o desafio de abrir caminhos para esse porvir, traçando reflexões sobre o sentido da existência humana.

Para que ocorra a efetivação da EA nas práticas docentes, é preciso considerar que os conhecimentos escolares são decorrentes de um processo de construção social, ao mesmo tempo compartilhados e negociados entre os diversos grupos que compõem está dinâmica, no qual a temática ambiental, no processo educativo-escolar precisa integrar a prática cotidiana docente (TARDIF, 2002; TORALES, 2013).

No entanto, apesar da EA fazer parte dos currículos escolares, somente será efetivada, à medida que os professores reconhecerem sua importância em suas áreas de conhecimento e assumirem a responsabilidade de inclui-la em suas práxis educativa, sendo que a inserção da dimensão ambiental nas práticas escolares, depende da interpretação feita pelos professores, e suas reflexões sobre os aspectos socioambientais do meio em que estão inseridos (SAUVÉ, 2001). 
Para tanto, é preciso que os professores compreendam a complexidade da questão ambiental e suas implicações na vida cotidiana dos indivíduos, o que nos remete a compreender a relação entre a forma como os professores constroem seus saberes, e os integram a sua prática docente, como elementos fundamentais para entender e repensar a inserção da EA no ensino formal.

Assim, a mudança no processo educativo precisa levar em conta a cultura arraigada dos professores em lidar com o conhecimento de forma fragmentada e a própria organização do tempo de trabalho nas escolas. Por isso, é fundamental discutir com esses atores o sentido dessa proposta e a forma de traduzi-las em ações educativas para o bem da comunidade escolar (COIMBRA, 2006).

O processo de construção da realidade socioambiental se concretiza através do fazer pedagógico, considerando que os professores se posicionam como educador e como cidadão, com um caráter não estritamente pedagógico, mas também político, voltando-se para uma práxis de transformação da sociedade, em busca de uma sustentabilidade pautada em novos paradigmas (GUIMARÃES, 2011), onde a EA como educação política busca questionar as políticas atuais, bem como a educação escolar e extraescolar.

Logo, a EA ganha uma dimensão pedagógica no momento em que instituem espaços efetivos de questionamentos, encontros, confronto e negociação entre projeto político, universo cultural e interesses sociais diferentes, onde a ecopedagogia, como forma de fazer educação, tem a sustentabilidade como princípio educativo (GADOTTI, 2000).

Nesta perspectiva, Morales (2009) aborda que a questão ambiental necessita estabelecer uma relação dialógica entre o fazer e o aprender e o transformar, pois estes são elementos fundamentais para uma EA crítica, transformadora e emancipatória, uma vez que para se alcançar a sustentabilidade equitativa é necessário um processo de aprendizagem permanente (LEFF, 2010).

Neste sentido, Guimarães (2011) aborda que a EA volta-se para uma ação reflexiva (teoria e prática-práxis) de intervenção em uma realidade complexa, pois seus conteúdos não estão trilhados nos livros, mas na realidade socioambiental vivenciada pela 
ISSN- 1413-8638

E-ISSN - 2238-5533

v. 22, n. 2, p. 173-190, 2017

comunidade escolar, que vai além dos muros da escola, fato que a torna uma educação política voltada para a transformação da sociedade em busca da sustentabilidade.

A transmissão de valores e de atitudes são um dos pilares da EA, na formação cultural da subjetividade individual, como um dos indicadores educativos, sendo a repercussão do trabalho realizado pelos docentes na formação de gerações de estudantes, precisa de uma análise do comportamento pedagógico desses profissionais, especialmente em sua ação frente às demandas socioambientais, a fim de identificar os fatores que influem e/ou determinam sua práxis.

Outro aspecto relevante na ação dos professores é o papel que exercem na composição de estratégias educacionais capazes de mobilizar a comunidade escolar em prol de ações socioambientais, tendo em vista que sobre seus ombros repousa a missão educativa da escola, pois trabalhar o conhecimento sob uma ótica de significado para a vida é desenvolver atitudes e habilidade congruentes para que o sentido de aprender possa reforçar o ideário da Educação Ambiental no círculo escolar.

No entanto, Tozzoni-Reis (2008, p. 58) afirma que a EA no ensino formal é frequentemente tratada como iniciativa individual, como tema periférico das disciplinas, "são iniciativas muito tímidas, não existe preocupação oficial com a problemática ambiental no ensino superior", para tanto, é necessário esforços na inserção da EA nos processos de formação de professores, que se articulem aos conteúdos críticos e reflexivos que se pautem pela busca da autonomia, contribuindo para a apropriação de uma prática pedagógica autônoma e consistente voltada as questões socioambientais no âmbito formal (GUIMARÃES, 2004).

Por outro lado, é evidente que os avanços da EA na educação básica acabam responsabilizando os professores que é colocado diante de exigências às quais ele responde com dificuldade e para as quais os cursos de formação inicial pouco contribuem. Além disso, Loureiro (2009) ressalta que as práticas pedagógicas que focalizam as questões ambientais, mostram que os professores ainda não conseguiram superar a dicotomia entre teoria e prática, para tanto, é necessário considerar o conhecimento pré-existente dos alunos, como elementos fundamental no processo pedagógico (FREIRE, 1996). 
Diante deste quadro, pode-se afirmar que a EA está definitivamente incorporada à escola, embora de forma enfraquecida, fragilizada, inspirada ainda por uma concepção única e consensual. No entanto, a formação dos professores, junto com outros elementos que atuam no contexto escolar, é parte do processo de incorporação do tema no âmbito curricular, pois, sem que haja uma compreensão das questões ambientais em seus aspectos políticos, ideológicos, culturais, sociais e econômicos, as ações tendem a se tornar descaracterizadas como alternativas para a renovação da prática pedagógica.

\section{FERRAMENTAS PEDAGÓGICAS NA CONSTRUÇÃO DO CONHECIMENTO EM UMA EDUCAÇÃO AMBIENTAL HOLÍSTICA}

O uso do grupo focal como técnica em pesquisas qualitativas em ciências humanas e sociais, é um dos instrumentos que pode ser utilizado como ferramenta pedagógica para a compreensão das percepções e inter-relações existente entre os indivíduos no processo de formação de educadores ambientais, assim como na sociabilidade do conhecimento entre os indivíduos que contribuem para a compreensão de objetos de estudos, principalmente na área da educação.

Destacamos que um dos desafios para a implementação de uma pedagogia critico social dos conteúdos no ambiente escolar, tem sido a convivência e o compartilhar de conhecimento entre os educadores no ambiente escolar, o qual tem se constituído como um dos principais desafios do cotidiano escola, pois de modo geral, não há diálogo entre os docentes no cotidiano escolar. Neste sentido, percebe-se que a escola é constituída por turnos, porém o compartilhar de saberes e conhecimentos é quase inexistente o que põe em cheque a integração dos currículos escolares de forma transversal e interdisciplinar interligado aos saberes dos educandos a serem discutidos no ambiente escolar integrado ao ambiente não formal de educação.

Segundo Borges e Santos (2005) o grupo focal é uma dentre as várias modalidades disponíveis de grupo de discussão em que os participantes dialogam sobre um tema particular, ao receberem estímulos apropriados para o debate. Neste sentido, Bellenger et al. (1976) enfatizam que o procedimento de ouvir-refletir-questionar, facilita respostas mais espontâneas dos participantes e oportuniza alto nível de envolvimento nas discussões. 
ISSN- 1413-8638

E-ISSN - 2238-5533

v. 22 , n. 2, p. 173-190, 2017

Neste sentido, Fleck (1986), o qual ressalta que o conhecimento ocorre numa dinâmica de interação entre o sujeito e o objeto mediado por uma dimensão que é social e culturalmente determinada, uma vez que não existe realidade absoluta, pois à medida que o conhecimento avança transforma inevitavelmente a realidade: o saber se modifica segundo o Estilo de Pensamento vigente, havendo mudanças, quando este se desenvolve, ampliando-se e se transformando, pois um Coletivo de Pensamento existe sempre que ocorrer trocas de ideias entre os membros do coletivo.

Portanto, ao valorizarmos a conversação entre as pessoas, cada uma expressando pensamentos que não estariam em condições de produzir por si mesmo ou em outra companhia. [...]. "O coletivo de pensamento consiste em distintos indivíduos e tem, assim mesmo, sua forma psíquica particular e suas leis especiais de comportamento" (FLECK, 1986, p. 91). Andrade e Amorin (2010) complementam a contribuição do Grupo Focal para entender como os sujeitos reagem a uma determinada temática num processo de interação grupal, fato que nos permitiu compreender os saberes docentes no decorrer do percurso metodológico, como um recurso para melhor compreender o processo de construção das percepções, saberes e atitudes de determinados grupos sociais.

Consideramos as concepções de Morgan (1998); Gatti (2005); Weller (2006); Flick (2009) e Andrade e Amorin (2010), os quais afirmam que os grupos focais possibilitam uma análise das percepções individuais, das interações coletivas e de aspectos recorrentes ao cotidiano dos sujeitos. Além disso, o Grupo Focal pode facilitar o aparecimento de ideias e de experiências que normalmente são esquecidas na efetivação de currículo educativo transversal e interdisciplinar.

Gatti (2005) considera que uma característica distintiva do grupo focal é a interação, o que nos permite afirmar esses momentos possibilitam uma aproximação entre os professores, o que facilita a troca de experiência e parcerias para o desenvolvimento de atividades transversais e interdisciplinares, isto indica uma estratégia de cooperação ética entre os profissionais e o respeito pelo trabalho do outro, ou até mesmo um incentivo em buscar novas alternativas metodológicas para o processo de ensino-aprendizagem. 


\section{VIVÊNCIA E SABERES PEDAGÓGICOS EM UMA ESCOLA RIBEIRINHA AMAZÔNICA}

Em 2015 o Grupo de Integração Socioambiental e Educacional (GISAE), aplicou a técnica do grupo focal como ferramenta pedagógica em um projeto piloto sobre a formação de educadores em uma escola ribeirinha amazônica, onde partimos do pressuposto de que os saberes e vivências dos educandos precisariam está inserido na pratica educativa como parte do seu fazer pedagógico, tendo o diálogo como base fundamental nesse processo, como nos afirma Paulo Freire (2002, p. 51 ) ao enfatizar que "O sujeito que se abre e aos outros inaugura com seu gesto a relação dialógica em que se confirma como inquietação e curiosidade".

Acreditamos que a implementação de uma estratégia pedagógica que possibilite a aproximação entre os educadores no ambiente escolar, talvez seja uma alternativa de aproximação e integração das atividades curriculares com os saberes e vivências dos educandos. Destacamos que no decorrer do primeiro encontro entre os professores, percebemos que muitos se sentiam envergonhados por não conhecerem uns os outros, porém no desenrolar da metodologia e nos momentos de reflexão e discussão sobre suas atividades curriculares, experiências e saberes cotidianos foi perceptível o interesse em conhecer o trabalho do outro.

Ressalta-se que um dos momentos marcantes na implementação dos momentos de reflexão foi o fato da maioria dos professores relatarem que as reuniões pedagógicas deveriam proporcionar momentos de conversação e diálogo uns com os outros, pois no geral serve apenas como mecanismo de cobrança e não de conversação pedagógica, o que nos possibilita afirmar a importância de momentos de reflexão que considere as vivências e saberes de cada educador que compõe o ambiente escolar.

Neste sentido, refletimos sobre a necessidade de repensarmos os métodos pedagógicos para a implementação de um currículo transversal e interdisciplinar, e principalmente nossa compreensão de educação e o papel do educador nesse processo, precisamos entender que a escola não se constitui de paredes, mas de pessoas que possuem vivências e saberes essenciais para uma práxis educativa transformadora.

Neste sentido, Freire (2002) ressalta que a prática docente é envolvida por uma dialética entre o fazer e o pensar sobre o que fazer, porém enfatiza que os saberes da 
experiência é um saber ingênuo que precisa de rigorosidade, o que cabe ao educador assumir a responsabilidade de refletir e construir conhecimentos sistêmicos refletindo sobre sua prática, tornando-a critica. Portanto a formação permanente dos educadores é um momento de reflexão sobre a prática, essencial para o desenvolvimento de práxis educativa libertadora.

Percebemos que muitas vezes o fracasso educacional está relacionado a ausência de diálogo entre os profissionais da educação que estão na escola, pois estamos acostumados com métodos tradicionais que já não atendem as demandas atuais, e esquecemos que a escola tem se estruturado de forma diferenciada, uma vez que os discentes possuem vivências sociais diferentes que chegam na escola, e questionamos até que ponto a escola tem feito diferença na vida dos educandos? Será que estamos educando para a cidadania ou apenas reforçando o fracasso escolar? Não queremos com isso discutir os conteúdos curriculares ou as políticas educacionais, mas como possibilitar a compreensão dos saberes socioambientais vivenciados pela comunidade escolar.

Cabe destacar que o uso de temas geradores de forma transversal e interdisciplinar de modo geral pouco tem sido compreendido pelo educador, no entanto, a técnica do grupo focal pode ser utilizada como uma ferramenta para a compreensão da educação para além dos muros da escola, numa visão mais complexa de educação em seu contexto social, político, econômico, ambiental e cultural, traçando alternativas de superar os obstáculos na efetivação de uma educação emancipatória e libertária. Assim, Freire (1993) afirma que o tema gerador faz ruptura na concepção de um ensino disciplinador que aborda o saber de forma cartesiana. E na perspectiva do grupo focal se tem possibilidade de articular o saber as relações que geram o movimento de construção do conhecimento.

\section{INDICADORES PARA UMA PRÁXIS TRANSVERSAL DE EDUCADORES AMBIENTAIS}

A educação ambiental como parte dos referenciais a ser apreciado no Projeto Político Pedagógico destaca-se como instrumento interdisciplinar e transversal das diversas áreas do conhecimento que compõe com o currículo escolar, considerando suas 
especificidades nas diversas propostas de ação socioeducativa, o que possibilita refletirmos sobre como isto incide no cotidiano escolar, o que permitirá a todos os envolvidos no processo educativo a compreender o fazer pedagógico em sua complexidade, e não atrela-lo apenas a sala de aula, mas aos fatores socioculturais, políticos e econômicos existentes, intercalando o currículo oficial com as vivências cotidianas no processo de ensino e aprendizagem, como podemos verificar na figura 01 .

Figura 01. Correlação da educação ambiental com o currículo oficial e os conhecimentos extraescolares.
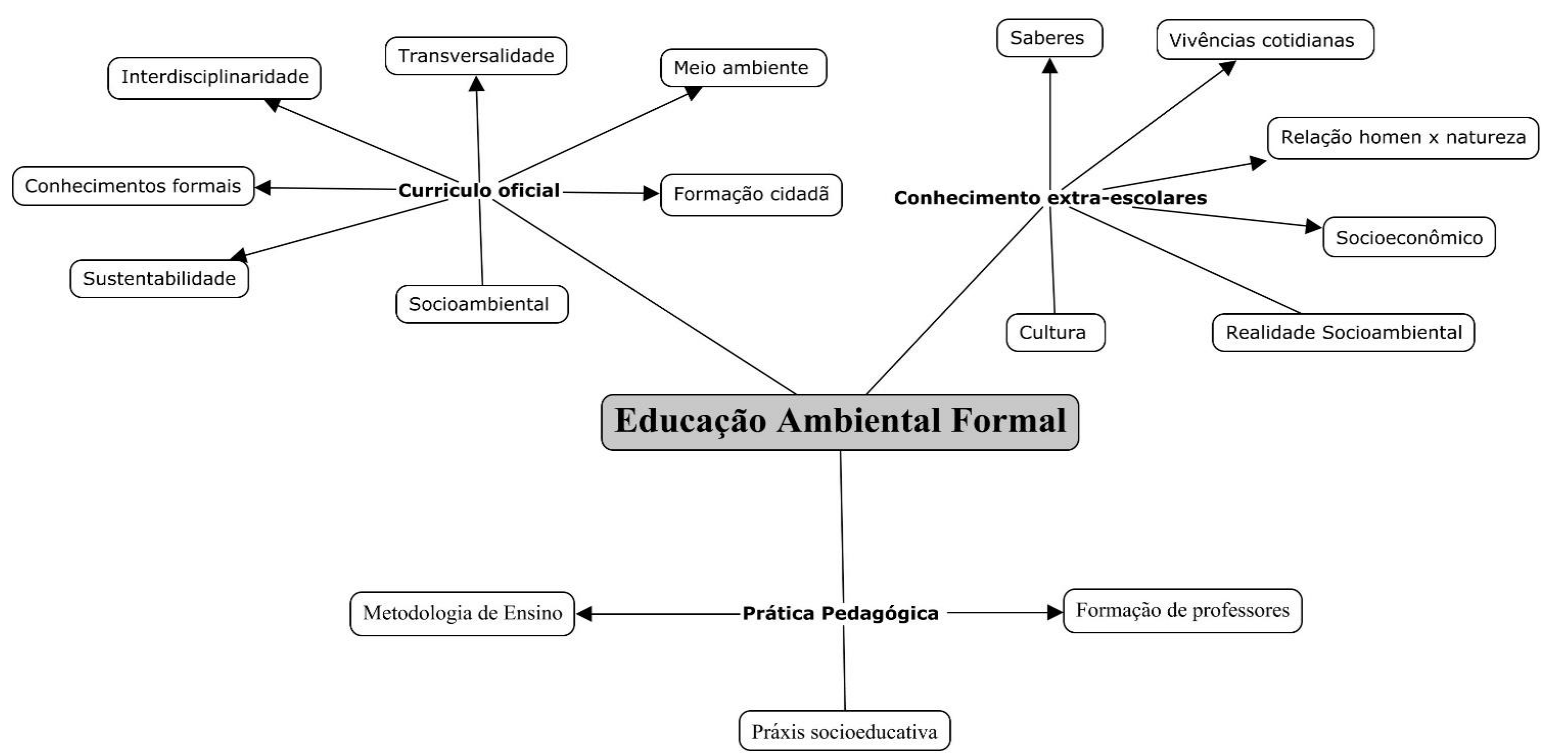

Fonte: Elaborado pelos autores (2017).

Destacamos que não basta a educação ambiental está inserida nos documentos oficiais educativos e no Projeto Político Pedagógico da escola, mas sim às causas, aos desafios, aos sonhos, à história e à cultura dos povos, precisamos enfatizar a educação ambiental dentro do projeto educativo que focalize o seu papel na reconstrução do sistema de relações entre as pessoas, a sociedade e o ambiente natural.

Neste sentido, a Educação Ambiental deve ser vivenciado por meio de experiências significativas transversais e interdisciplinares, que garantam aos sujeitos a possibilidade de adquirir conhecimentos e competências essenciais para torna-los aptos a resolver 
problemas socioambientais que os atingem tanto no âmbito individual quanto coletivo (GOMES, 2017).

Para tanto, é preciso que os educadores ambientais compreendam a complexidade da questão ambiental e suas implicações na vida cotidiana, o que nos remete a entender a relação entre a forma como os professores constroem seus saberes, e os integram a sua prática docente, como elementos fundamentais para entender e repensar a inserção da EA no ensino formal.

As práticas pedagógicas devem ser orientadas por saberes oriundos de diversas fontes, sejam formais ou não formais. Nesse aspecto leva-se em conta os saberes próprios do viver amazônico, que congregam experiências múltiplas e singulares pois segundo Brandão (2007, p.17) "tudo que se sabe aos poucos se adquire por viver muito e diferentes situações de trocas entre pessoas, com o corpo, com a consciência, com o corpo-e-a-consciência". Assim traduzimos nossa compreensão sobre educação vista sob diversas formas, muitas vezes diferenciadas e pautadas na vivência de cada grupo e, consequentemente de seus saberes.

Freire (2006, p.39) destaca também que é preciso que "a educação esteja em seu conteúdo, em seus programas e em seu método, adaptada ao fim que se persegue: permitir ao homem chegar a ser sujeito", construindo, assim, um indivíduo que seja capaz de transformar a sua realidade e o mundo.

Desse modo, as práticas pedagógicas buscam considerar não só a realidade do indivíduo, mas também o seu interesse e os seus saberes como fundamento para as ações educativas propostas, pois como alerta Vygotsky (1984) a aprendizagem deve ter como resultado a interação entre os indivíduos e o contexto que estão inseridos, contribuindo para que haja a construção de conhecimento que os ajudem a se integrar no processo de ensino e aprendizagem.

Diante disso, no contexto amazônico a prática pedagógica deve levar em consideração a cultura amazônica, aquela que tem na sua origem ou está influenciada pela cultura dos descendentes de índios e brancos, o caboclo, também denominada cultura cabocla (LOUREIRO, 2002).

Esta cultura apresenta-se como um mosaico colorido de mitos, ritos, crenças, valores, saberes e representações do universo caboclo que expressam o ser e viver 
amazônico e que precisam ser conhecido e valorizado considerando que tais saberes entre eles os referentes a sua biodiversidade quase sempre estão ausentes dos espaços escolares de grandes cidades amazônicas (FONSECA, 2003).

Autores como Freire $(1981,1992)$ e Brandão $(1995,2002)$ têm chamado atenção que os conteúdos culturais devem ser vistos como marco integrador de uma práxis educativa transformadora, considerando que o ato de educar se faz no interior da cultura em situações sociais de aprender-ensinar-aprender, ou seja "uma fração do modo de vida dos grupos sociais" está sempre presente nos processos educativos, sendo constantemente criada e recriada no saber, no ser ou no conviver.

Desse modo, ao compreender que a educação é parte da educação humana de tornar inteligível sua existência dotando-a de sentido, entendemos necessário que as condições históricas e culturais dos sujeitos envolvidos no processo educativo sejam consideradas, pois, a cultura fornece elemento que contribuem para formar a identidade do ser humano.

Entretanto, para que os saberes integrem as práticas educativas escolares de forma sistemática precisam de um lado que sejam concebidos por quem ensina-aprende como provenientes da prática social construída e construtora da humanidade, ou seja produto da vida social e, portanto compreendido como elementos indispensáveis na formação humana plena e por outro serem conhecidos, o que exige, de certo modo, apropriação da cultura que os sujeitos aprendentes estão emersos.

Assim, a educação escolar leva em conta a cultura local precisa inseri-la como conteúdo de ensino, de modo que os processos formativos possibilitem sua compreensão, pois como afirma Piaget e Inhelder (1982) o ser humano aprende quando trabalha com situações concretas, onde oportuniza o pensar, refletir, questionar, manipular materiais, propor soluções tendo como referência a vida cotidiana.

Um dos desafios que se coloca a escola é arrolar os diferentes tipos de conhecimento representativo dos contextos culturais em que vivem os sujeitos que dela participam, de forma a construir um desenho curricular, atividades e práticas educativas que possibilitem a formação de sujeitos sociais críticos e capazes de valorizar a cultura local. Este desfio está posto às escolas da Amazônia, pois mesmo que se tenham atualmente informação cientifica, cultural e tecnológica sobre a região estes saberes quase sempre estão distantes das práticas escolares cotidianas. 
ISSN- 1413-8638

E-ISSN - 2238-5533

v. 22, n. 2, p. 173-190, 2017

Autores diversos têm discutido que a socialização de informações sobre a cultura local, em programas educativos e outros de alcance da população podem gerar posturas de sua valorização (OLIVEIRA, 1994; PACHECO, 1995; LIMA, 2002).

Na Amazônia Brasileira, este território imenso e heterogêneo que integra água, floresta, minerais, sociobiodiversidade, dentre outras riquezas que se fazem necessário à difusão de informações que promovam sua sustentabilidade. Entretanto os dilemas que se colocam aos governos e as instituições sociais, incluindo a escola são: Quais as informações são prioritárias? Como definir essas necessidades? Como inserir os conhecimentos sobre a realidade amazônica nos processos de produção e socialização de informações no contexto escolar?

Destacamos que, poucos estudos tem se debruçado em investigar essas questões no contexto amazônico, para tanto, citamos a tese de doutorado desenvolvida por Fonseca (2003), a qual avaliou a compreensão do tema biodiversidade e desenvolvimento sustentável entre professores e alunos do ensino médio e a inclusão dessa discussão em livros didáticos e propostas de programas de ingresso ao ensino superior de instituições públicas e particulares do município de Belém do Pará, constatando a necessidade da inserção desses conhecimentos relacionados à realidade amazônica no contexto escolar, entretanto, não indica conteúdo a serem trabalhados na prática educativa.

Objetivando dar continuidade ao estudos iniciados por Fonseca (2003), o Núcleo de Estudos em Educação Científica, Ambiental e práticas sociais - NECAPS da Universidade do Estado do Pará, realizou em 2014 a pesquisa intitulada "Saberes Necessários para a inclusão de temas ambientais no contexto escolar", no qual buscou identificar os saberes necessários a uma formação básica que permita aos estudantes conhecer a realidade da sociobiodiversidade amazônica (FONSECA; SILVA, 2014). Os resultados obtidos pelo NECAPS aponta que os problemas socioambientais é o mais lembrado pelos pesquisados, o que indica estarem atentos as problemáticas que a região enfrenta, assim como a necessidade desse tipo de abordagem no contexto escolar.

Diante disso, pode-se afirmar que a formação dos professores, junto com outros elementos que atuam no contexto escolar, é parte do processo de incorporação do tema no âmbito curricular, pois, sem que haja uma compreensão das questões ambientais em seus aspectos políticos, ideológicos, culturais, sociais e econômicos, as ações tendem a se tornar descaracterizadas como alternativas para a renovação da prática pedagógica. 


\section{CONSIDERAÇÕES FINAIS}

Acreditamos que a implementação de uma estratégia pedagógica que possibilite a aproximação entre os educadores no ambiente escolar, talvez seja uma alternativa de integração das atividades curriculares com os saberes e vivências dos educandos, tendo o grupo focal como estratégia metodológica de aproximação e dialogo no ambiente escolar.

Podemos afirmar que a formação dos professores, junto com outros elementos que atuam no contexto escolar, é parte do processo de incorporação do tema no âmbito curricular, pois, sem que haja uma compreensão das questões ambientais em seus aspectos políticos, ideológicos, culturais, sociais e econômicos, as ações tendem a se tornar descaracterizadas como alternativas para a renovação da prática pedagógica.

Defendemos que as pesquisas sobre a EA no contexto escolar analisem as decisões curriculares das equipes pedagógicas, levando em conta a dinâmica de seus contextos socioambientais e culturais. Logo, é preciso que os educadores ambientais compreendam a complexidade da questão socioambiental e suas implicações na vida cotidiana, o que nos remete a entender a relação entre a forma como os professores constroem seus saberes, e os integram a sua prática docente, como elementos fundamentais para entender e repensar a inserção da EA no ensino formal. Diante disso, os autores sugerem: 1) Desenvolver Palestras/oficina, a partir das demandas apontadas nos grupos focais; 2) Discutir a temática socioambiental no decorrer do planejamento da escola, para que esta possa ser inserida no Projeto Político Pedagógico; 3) Criar estratégias para compreensão da EA dentro de uma complexidade transversal, através de encontros regulares de formação de professores; 4) Traçar metas na formação de educadores ambientais amazônicos, tendo como base o modo de vida dos educandos e das experiências e vivências pessoais dos docentes.

\section{Referências}

AB' SABER, A. N. “(Re) conceituando a educação ambiental”. In: MAGALHÃES, L. E. A questão ambiental. São Paulo: terra graph, 1994. 
ANDRADE, M.; AMORIN, V. Grupo focal: a pesquisa com foco na interação dos sujeitos. In: MARCONDES, M. I; TEIXEIRA, E.; OLIVEIRA, I. A. (Org). Metodologias e técnicas de pesquisa em educação, Belém: EDUEPA, 2010.

BORGES, C.D; SANTOS, M. A. Aplicações metodológicas da técnica de Grupo Focal: fundamentos metodológicos, potencialidades e limites. Rev. SPAGESP, n.1, v.6, p. 7480, set., 2005 .

BELLENGER, D. N., BERNHARDT, K. L., GOLDSTUCKER, J. L. Qualitative Research in Marketing. Chicago: American Marketing Association, 1976. p. 7-28: Qualitative Research Techniques: focus group interviews.

BRANDÃO, C. R. A educação como cultura. Campinas: Mercado das Letras, 2002.

BRANDÃO, C. R. O que é educação?. São Paulo:Brasiliense, 1995.

CARVALHO, I.C.M. Educação Ambiental: a formação do sujeito ecológico. São Paulo: Cortez, 2012.

COIMBRA, A. S. O tratamento da educação ambiental nas conferências ambientais e a questão da transversalidade. Rev. Eletrônica Mestr. Educ. Ambient., v. 16, p.131-140, set., 2006.

FLECK, L. La génesis y el desarrollo de un hecho científico. Madrid: Alianza Editorial, 1986.

FREIRE, P. Pedagogia da autonomia: saberes necessários à prática educativa. São Paulo: Paz e Terra, 1996.

FREIRE, P. Pedagogia da Autonomia: saberes necessários à prática educativa. São Paulo: Paz e Terra, 2002.

FREIRE, P. Pedagogia do oprimido. São Paulo: Paz e terra, 1993

FREIRE, P. Pedagogia da Esperança: um reencontro com a Pedagogia do Oprimido. São Paulo: Paz e Terra,1992.

FREIRE, P. Ação cultural para a liberdade. Rio de Janeiro: Paz e Terra, 1981.

FREIRE, P. \& SHOR, I. Medo e ousadia: o cotidiano do professor. Rio de janeiro: Paz e Terra, 2006.

FONSECA, M. J. C. F. A. A biodiversidade e desenvolvimento sustentável em escolas do ensino médio em Belém do Pará. São Paulo, Educação e Pesquisa, v. 33, n.1, p. 6379, set/out., 2007. 
FONSECA, M. J. C. F; SILVA, S. C. J. Temas Amazônico no contexto escolar. Núcleo de Estudos em Educação Científica, Ambiental e Práticas Sociais - NECAPS, Belém, UEPA, 2014.

FONSECA, M. J.; C. F. A biodiversidade e desenvolvimento sustentável em escolas do ensino médio em Belém do Pará. Tese de Doutorado. Universidade Federal do Pará (UFPA), Belém, 2003.

FLICK, U. Introdução a pesquisa qualitativa. Porto Alegre: Artmed, 2009.

GUIMARÃES, M. A formação de educadores ambientais. São Paulo: papirus, 2011.

GUIMARÃES, M. Educação Ambiental Crítica. In: LAYRARGUES, P. P. (org.). Identidades da educação ambiental brasileira. Brasília: Ministério do Meio Ambiente, 2004.

GAZZINELLI, M. F. Representações dos (as) professores (as) e implementação de currículo de educação ambiental. Cadernos de Pesquisa, n. 115, p. 173-194, out., 2002 GADOTTI, M. Pedagogia da terra. São Paulo: Petrópolis, 2000.

GATTI, B. A. Grupo focal na pesquisa em ciências sociais e humanas.

GOMES, R. K. S. A teoria Fleckiana como subsidio a uma Educação Ambiental holística na práxis educativa docente. Rev. Eletrônica Mestr. Educ. Ambient., v. 34, n.1, p. 233-249, jan/junh., 2017

LEFF, E. Discursos sustentáveis. São Paulo: Cortez, 2010

LOUREIRO, C. F. B. Trajetórias e fundamentos da Educação Ambiental. São Paulo: Cortez, 2006.

LOUREIRO. C. F. B. Mundialização do capital, sustentabilidade democrática e políticas públicas: problematizando os caminhos da educação ambiental. Revista ambiente e educação, n. 19, v. 14, p.11 -22, jan/junh, 2009.

LIMA, G. F. C. Crise ambiental, educação e cidadania: os desafios da sustentabilidade emancipatória. In: Loureiro, C. F. B. et. al (Org.). Educação ambiental: repensando o espaço da cidadania. São Paulo: Cortez, 2002.

LOUREIRO, V. R. Amazônia: uma história de perdas e danos, um futuro a (re) construir. Estudos Avançados, v.16, n. 45, p.107-121, out., 2002. 
MORALES, A. G. M. Processo de institucionalização da educação ambiental: tendências, correntes e concepções. Pesquisa em Educação Ambiental, n. 1, v. 4, p. 159-175, set. 2009

MORGAN, D. L.; KRUEGER, R. A. (eds). The focus group kit. Thousand Oaks, CA: Sage, 1998

OLIVEIRA, E. (org.). Amazônia: uma proposta interdisciplinar em educação ambiental. Brasília: IBAMA, 1994.

PACHECO, J. A. Do componente nacional aos componentes curriculares regionais e locais. Braga; Universidade do Minho, 1995.

PIAGET, J.; INHELDER, B. A psicologia da criança. São Paulo: Difel, 1982.

PRIMACK, R.; RODRIGUES, E. Biologia da Conservação. Londrina: Planta, 2001.

SAUVÉ, L. Éducation et environnement à l'école secondaire: modèles d'intervention en éducation relative à environnement développés par. Montreal, Quebéc: Les Éditions Logiques, 2001.

TOZONNI- REIS, M. F. C. Educação ambiental: natureza, razão e história. Campinas São Paulo: autores associados, 2008.

TORALES, M. A. A inserção da educação ambiental no currículo escolar e o papel dos (as) professores (as): da ação escolar a ação educativa-comunitária como compromisso político ideológico. Rev. Eletrônica Mestr. Educ. Ambient., v. esp., p.1-15, 2013.

TEIXEIRA, C.; TORALES, M. A. A questão ambiental e a formação de professores para a educação básica: um olhar sobre as licenciaturas. Educar em Revista. Ed. Especial n. 3, p. 127-144, 2014.

TARDIF, M. Saberes docentes e formação profissional. Petrópolis: Vozes, 2002. VIGOTSKY, L. S. A formação social da mente. São Paulo: Martins Fontes, 1984. WELLER, W. Grupos de discussão na pesquisa com adolescentes: aportes teóricosmetodológicos e analise de uma experiência com o método. Educação e pesquisa, n. 2, v. 32, p. 241-260, jan/junh., 2006. 